\title{
INDENTATION RESISTANCE OF AN ALUMINIUM FOAM
}

\author{
O.B. Olurin, N.A. Fleck ${ }^{\dagger}$ and M.F. Ashby \\ Cambridge University Engineering Department, Cambridge, CB2 1PZ, UK \\ (Received May 15, 1999) \\ (Accepted in revised form July 3, 2000)
}

Keywords: Aluminium foam; Indentation; Tear energy; Monotonic and cyclic loading

\section{Introduction}

Metallic foams are potential materials for light-weight structural sandwich panels and energy absorbing devices, amongst others. A potential failure mode of sandwich panels is that from impacts associated with poor handling and from indentation loading intentional or unintentional. Early work on the indentation of foams has suggested that it is controlled to a large extent by its compressive strength [1,2]. Preliminary work on the indentation of foams was presented by Andrews et al. [3], Onck et al. [4], Gibson and Ashby [5], Tulliani et al. [6], Stupak and Donovan [7] and Prakash et al. [8]. The average indentation pressure was reported as a function of indenter geometry and contact area, with limited experimental data. The aim of this work is to characterise the indentation resistance of metallic foams for different indenter geometries. Tear energies are measured and compared with mode I fracture energies.

\section{$\underline{\text { 2. Material Specification and Mechanical Testing Strategy }}$}

Panels of Alporas ${ }^{1}$ metallic foam of dimensions $300 \times 300 \times 50 \mathrm{~mm}$, of relative density $\bar{\rho}=8-15 \%$ were tested. Alporas is a closed cell aluminium alloy foam, consisting of $0.4-2 \mathrm{wt} . \%$ of calcium to enhance viscosity and $<2$ wt.\% of titanium hydride powder added as a foaming agent. The titanium released from the foaming agent and the calcium remain in the aluminium after the processing has been completed: the cell walls contain the oxides $\mathrm{CaO}$ and $\mathrm{CaAl}_{2} \mathrm{O}_{4}$. It is a cast aluminium alloy foam and details of the manufacturing technique can be found in reference [9]. Details of the strategy for indentation tests are as follows.

Axisymmetric indentation tests were performed on blocks of Alporas foam of relative density $\bar{\rho}=$ $8-15 \%$ using flat-bottomed circular cylindrical punches of diameters $2 a$, with $5 \mathrm{~mm} \leq 2 a \leq 35 \mathrm{~mm}$. To minimise the effects of friction, the indenters were lubricated with PTFE spray. The indenters were pushed to about $45 \mathrm{~mm}$ depth into the Alporas foam blocks. Precautions were taken to ensure that tests were free of edge effects-all indentations were performed at a distance of 1 to 2 indenter diameters away from all free edges, and about one indenter diameter away from previous indentation locations. Recall that edge effects are avoided if the foam plate is at least two indenter diameters in thickness

\footnotetext{
$\pitchfork$ To whom all correspondence should be addressed.

${ }^{1}$ Supplier: Shinko wire company Ltd., 10-1, Nakahama-machi, Amagasaki-shi, 660 Japan.
} 


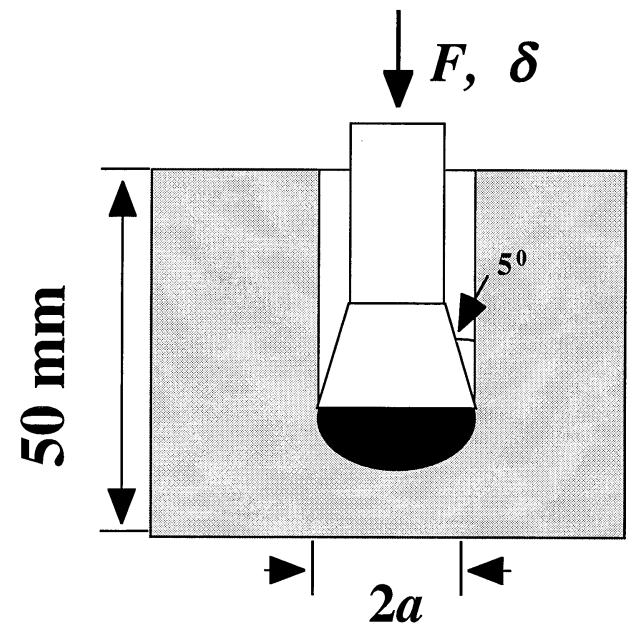

(a)

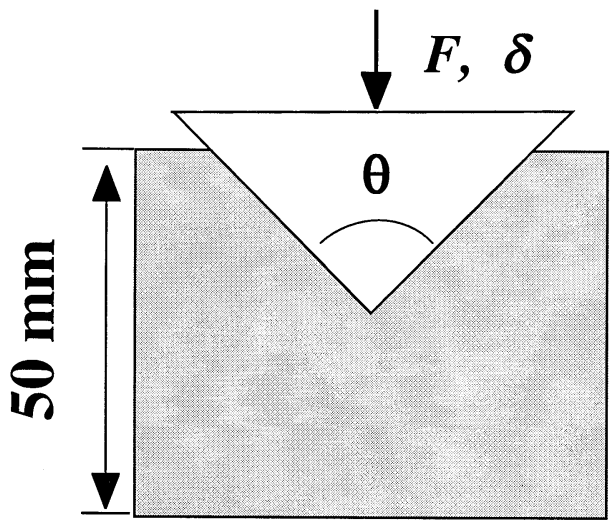

(b)

Figure 1. (a) Sketch of axisymmetric indentation for a flat-bottomed circular cylindrical punch. (b) Schematic showing 2D plane strain indentation for a wedge indenter.

[10] - this condition was strictly observed in this work. The shanks of all indenters were chamfered at an angle of $5^{\circ}$, as shown in Figure 1a, to eliminate friction.

The effect of indenter shape on the measured indentation load was characterised using flat-bottomed circular cylindrical, flat-plate and wedge indenters. Flat plate indenters of out-of-plane dimension $L=$ $50 \mathrm{~mm}$ and indenter width $W=5,10,15,20,25$ and $35 \mathrm{~mm}$, wedge indenters of included angles $\theta=$ $90^{\circ}, 120^{\circ}$ and $150^{\circ}$ and flat-bottomed circular cylindrical punches (same dimension as earlier described in this section) were used for these tests (see Figures 1 and 2). For the flat-plate and wedge indenters, the Alporas foam plate was placed on its side, so that the indenters length $L$ coincided with the plate thickness $(50 \mathrm{~mm})$. The axisymmetric indentations were performed on the face of the plate. For all geometries, shallow indentations were performed on Alporas foam $(\bar{\rho}=8 \%)$ to a depth of about $10 \mathrm{~mm}$. Tests were performed on a servo-hydraulic testing machine in displacement control at room temperature

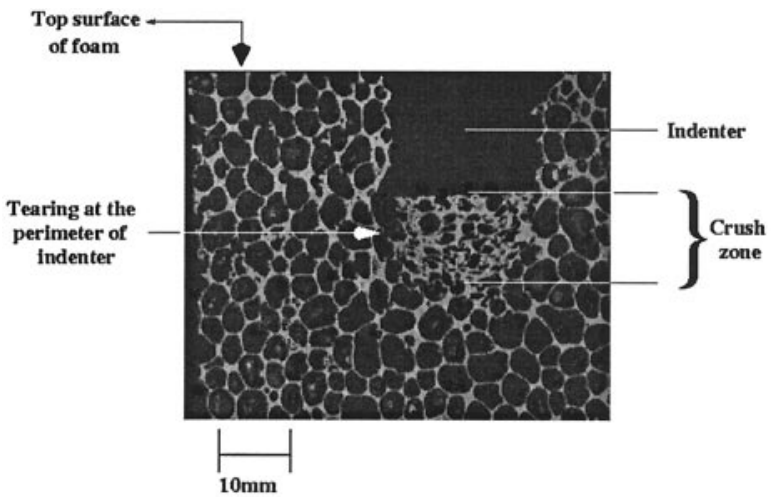

Figure 2. Optical micrograph of Alporas metallic foam after indentation. 


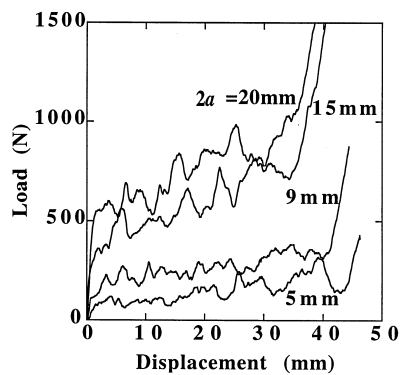

Figure 3. Indentation load-deflection curves for Alporas foam $(\bar{\rho}=8 \%)$, for circular flat-bottomed punches.

and at a rate of $0.08 \mathrm{mms}^{-1}$, and the load and the load-line displacement were recorded. Figure 1 shows a schematic of the indentation test set-ups.

Cyclic indentation tests were also performed in load control at a test frequency of $20 \mathrm{~Hz}$ and at a load ratio $R=0.1$. The load ratio $R$ is defined as

$$
R=\frac{|F|_{\min }}{|F|_{\max }}
$$

where $|F|_{\min }$ and $|F|_{\max }$ are the magnitudes of the peak applied cyclic loads. The fatigue tests were performed with flat-bottomed circular cylindrical punches of diameter $2 a=15 \mathrm{~mm}$ on Alporas foam $(\bar{\rho}=8 \%)$. The maximum and minimum values of the load and the displacement, and the number of fatigue cycles were recorded during the tests.

\section{Monotonic Loading}

\subsection{Deformation Response for Flat-Bottomed Circular Cylindrical Punches}

Typical load-displacement (or penetration) curves for indentation of Alporas foam $(\bar{\rho}=8 \%)$ are shown in Figure 3 for a range of indenter diameters $2 a$. The load-displacement indentation response of Alporas foam is similar to that in monotonic compression (see $[9,11]$ ). The load increases with displacement approximately linearly until a displacement of about $2 \mathrm{~mm}$. It then approaches a plateau value, prior to an increase in stress when there is an interaction with the back face of the plate. The plateau load (normalised by the radius of indenter), measured at a displacement of $25 \mathrm{~mm}$, is plotted against indenter radius in Figure 4. The normalised plateau load increases linearly with the diameter of indenter, and so the average pressure $\bar{P}$ decreases with increasing diameter until a plateau value is attained. Results on shallow indentation of Alporas foam $(\bar{\rho}=8 \%)$ have been reported by Andrews et al. [3], and are included in Figure 4 for comparison.

The oscillations in the load-displacement response are due to repeating cycles of yield, collapse and densification, see Figure 3. As deformation progresses, the indenter is supported by a continuously increasing crushed zone of compacted material, as shown in the cross-section of Figure 2. This results in a steeper load-displacement curve, in comparison with a monotonic compression load-displacement curve.

Since metallic foams are plastically compressible with a plastic Poisson's ratio near zero [12], axial compression results in very little lateral spreading of the foam beneath the indenter.

The total force on indenter is the sum of that to crush the foam beneath the indenter and that required to tear it at the edges of the indenter, that is 


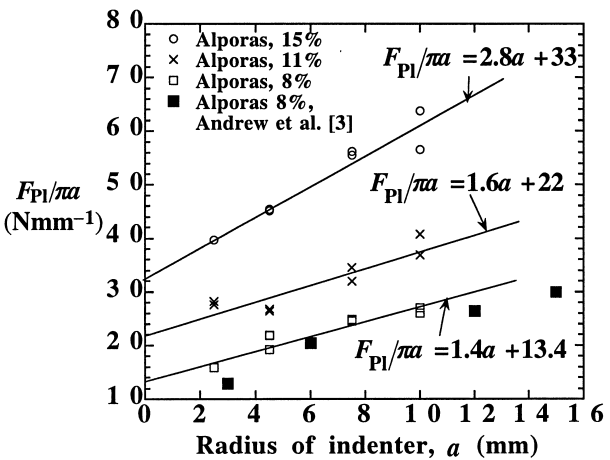

Figure 4. Normalised plateau load versus indenter radius for Alporas metallic foam—comparison of results for deep indentation of Alporas metallic foam with shallow indentation of Alporas metallic foam, $\bar{\rho}=8 \%$, from Andrews et al. [3].

$$
\begin{gathered}
F=F_{\text {crushing }}+F_{\text {tearing }} \\
F=\pi a^{2} \sigma_{\mathrm{pl}}^{*}+2 \pi a \gamma \\
\frac{F}{\pi a}=a \sigma_{\mathrm{pl}}^{*}+2 \gamma
\end{gathered}
$$

where $F$ is the total load, $a$ is the radius of indenter, $\sigma_{\mathrm{pl}}^{*}$ is the compressive plateau stress of the foam and $\gamma$ is its tear energy. Figure 4 shows a plot of Equation 3, fitted to the data, from which the plateau stress $\sigma_{\mathrm{pl}}^{*}$ and tear energy $\gamma$ are determined. Rearranging Equation 3 gives

$$
\frac{F}{\pi a^{2}}=\bar{P}=\sigma_{\mathrm{pl}}^{*}+\frac{2 \gamma}{a}
$$

where $\bar{P}$ is the total indentation pressure. Figure 5 shows a comparison of the extracted tear energy with that measured from bearing failure (see $[9,13]$ ), and from mode I initiation and steady state fracture energies in $J$-tests (see [11]). The tear energy is considerably higher than the initiation mode I fracture energy $J_{I C}$, but of the same order of magnitude as the mode I steady state fracture energy $J_{S S}$.

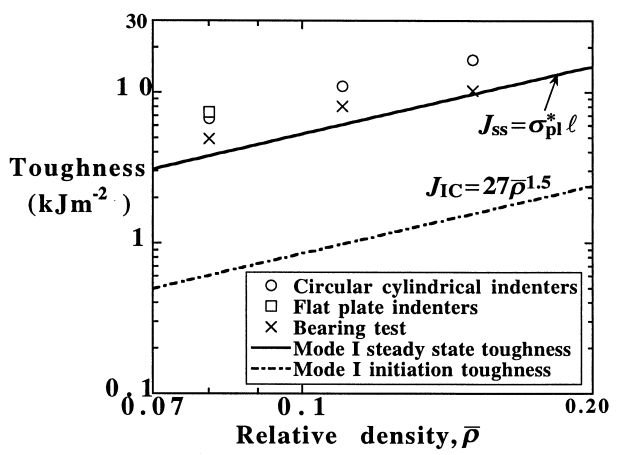

Figure 5. The effect of foam density on tear energy - comparison of mode I fracture energy and tear energy. 


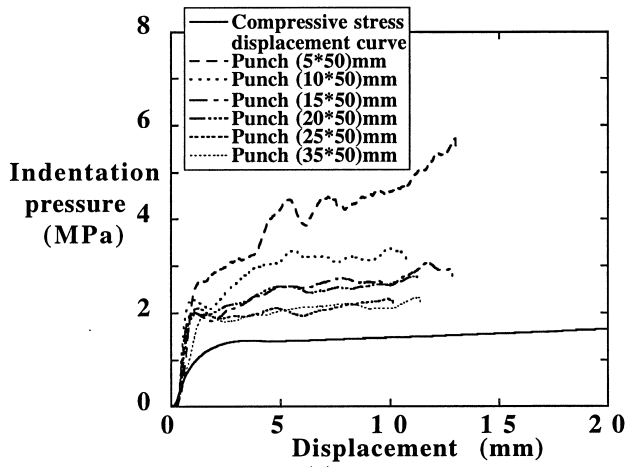

(a)

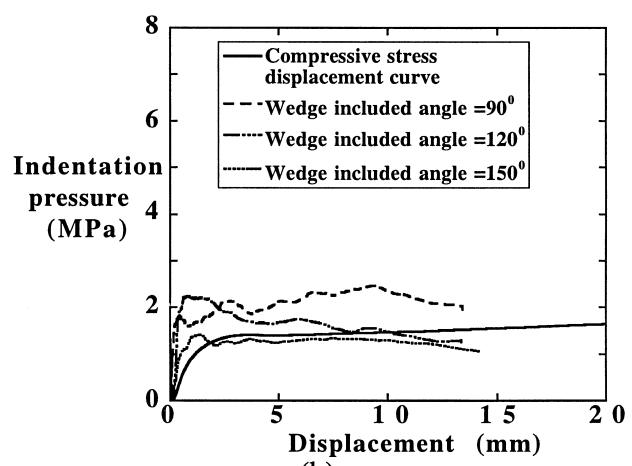

(b)

Figure 6. Typical indentation pressure versus displacement curves for Alporas foam $(\bar{\rho}=8 \%)$ using (a) Flat-plate indenter, and (b) Wedge indenter.

\subsection{Effect of Indenter Geometry on Indentation Pressure}

Typical average pressure versus displacement curves for quasi-static indentation of Alporas foam $(\bar{\rho}=$ $8 \%$ ) are presented in Figure $6 \mathrm{a}$ for flat-plate indenters and in Figure $6 \mathrm{~b}$ for wedge indenters. In both cases, the uniaxial compressive stress-displacement curve is included for comparison. The figures show the effect of indenter size for each geometry. Flat-plate and flat-bottomed circular cylindrical indenters show a significant size effect, with the indentation pressure independent of the indenter size only when $2 a / \ell$ or $W / \ell$ exceeds about 8 . Specific details for flat-plate and wedge indentations follow.

\section{Long Flat-Plate Punches, Plane Strain (Figure 6a)}

The average indentation pressure $\bar{P}$ decreases with increasing indenter width $W$, and reaches a limiting value slightly higher than the compressive plateau strength of the Alporas foam, when $W / \ell$ exceeds 8 .

The total indentation load is the sum of the crushing load and the load associated with the tearing of the cell walls at the perimeter. Equation 2 again applies,

$$
F=F_{\text {crushing }}+F_{\text {tearing }}
$$

where $F_{\text {crushing }}=\sigma_{\mathrm{pl}}^{*} L W$ and $F_{\text {tearing }}=2 \gamma L$. Then,

$$
\bar{P}=\frac{F}{L W}=\sigma_{\mathrm{pl}}^{*}+\frac{2 \gamma}{W}
$$

A plot of $\bar{P}$ against $1 / W$ allows $\sigma_{\mathrm{pl}}^{*}$ and $\gamma$ to be determined. The deduced values of the compressive plateau stress $\sigma_{\mathrm{pl}}^{*}(1.73 \mathrm{MPa})$ and the tear energy $\gamma\left(7.45 \mathrm{kJm}^{-2)}\right.$ are comparable to those for flat-bottomed circular cylindrical indenters.

\section{D Wedge Indenters, Plane Strain (Figure 6b)}

The mean indentation pressure (load divided by the nominal contact area) versus displacement is summarised as shown in Figure 6b. For a sharp wedge, it appears that there is small contribution from tearing on the total pressure, while for a blunt wedge $\left(\right.$ e.g. $\theta=150^{\circ}$ ), the indentation pressure is the same as the compressive plateau stress, suggesting no tearing, and none was observed. 


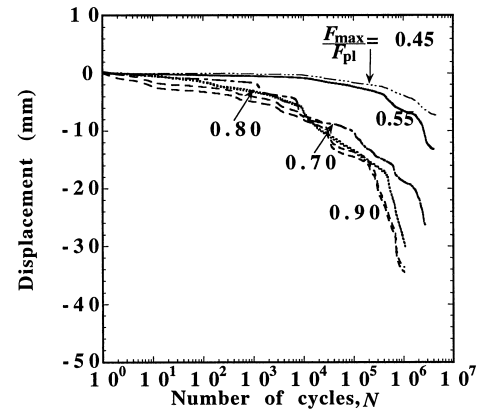

(a)

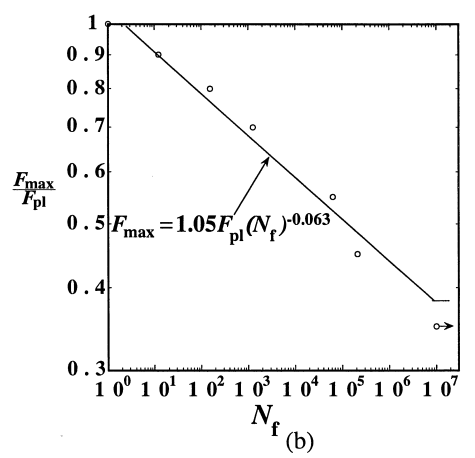

Figure 7. (a) Cumulative indentation displacement under compression-compression cyclic indentation loading of Alporas foam $(\bar{\rho}=8 \%)$. Indenter diameter $2 a=15 \mathrm{~mm}$ and load ratio $R=0.1$. (b) Associated S-N curve.

\section{$\underline{\text { 4. Cyclic Response to Indentation }}$}

Compression-compression cyclic indentation tests were performed on Alporas foam at a load ratio, $R=$ 0.1 , for a flat-bottomed circular cylindrical indenter. Typical plots of indentation displacement versus fatigue cycles are shown in Figure 7a. The maximum load $F_{\max }$ has been normalised by the plateau load $F_{\mathrm{pl}}$ for the same indenter subjected to monotonic loading (see Section 3.1). Progressive indentation was observed in fatigue. The observed penetration mechanism is similar to the shortening mechanism which has been reported for uniform compression-compression fatigue of metal foams by Harte et al. [14]. The cyclic indentation life is defined as the number of fatigue cycles for which the indentation depth equals the yield value in a monotonic test, corresponding to an indentation depth of about $2 \mathrm{~mm}$. The maximum fatigue load which the foam can withstand for $10^{7}$ cycles is about 0.35 times the indentation plateau load (see Figure 7b).

\section{Concluding Remarks}

Indentation loads have been measured for axisymmetric flat-bottomed circular cylindrical punches, flat-plate punches and 2D wedge indenters. The indentation pressure was observed to depend upon the indenter geometry and size, and upon the foam density. The mean indentation pressure decreases with increasing indenter size, until a limiting plateau pressure is attained. Tear energy was extracted from indentation test data; these were in agreement with similar data from bearing failure, and with the mode I steady state fracture energy. Cyclic indentation reduces the maximum safe indentation load that the foam can sustain to about 0.35 times the monotonic indentation load.

\section{$\underline{\text { Acknowledgments }}$}

The authors are grateful to DARPA/ONR for their financial support through MURI grant number N00014-1-96-1028 on the Ultralight Metal Structures project under sub-contract to Harvard University.

\section{References}

1. M. Wilsea, K. L. Johnson, and M. F. Ashby, Int. J. Mech. Sci. 17, 457 (1975).

2. M. C. Shaw and T. Sata, Int. J. Mech. Sci. 8, 469 (1966). 
3. E. W. Andrews, G. Gioux, P. Onck, and L. J. Gibson, Int. J. Mech. Sci. submitted.

4. P. Onck, E. W. Andrews, G. Gioux, and L. J. Gibson, Int. J. Mech. Sci. submitted.

5. L. J. Gibson and M. F. Ashby, Cellular Solids: Structure and Properties, 2nd edn., Cambridge University Press, Cambridge, UK (1997).

6. J.-M. Tulliani, L. Montanaro, T. J. Bell, and M. V. Swain, J. Am. Ceram. Soc. 82, 961 (1999).

7. P. R. Stupak and J. A. Donovan, Polym. Eng. Sci. 34, 857 (1994).

8. O. Prakash, H. Sang, and J. D. Embury, Mater. Sci. Eng. A. A199, 195 (1995).

9. O. B. Olurin, Deformation and Fracture of Cellular Foams, Ph.D. Thesis, Cambridge University Engineering Department (2000).

10. M. F. Ashby, A. G. Evans, N. A. Fleck, L. J. Gibson, J. W. Hutchinson, and H. N. G. Wadley, Metal Foams: A Design Guide, Butterworth Heinemann, Oxford, UK (2000).

11. O. B. Olurin, N. A. Fleck, and M. F. Ashby, Mater. Sci. Eng. A. to appear (2000).

12. V. S. Deshpande and N. A. Fleck, Isotropic Constitutive Models for Metallic Foams, J. Mech. Phys. Solids. 48, 1253 (2000).

13. O. B. Olurin, N. A. Fleck, and M. F. Ashby, J. Mater. Sci. 35, 1079 (2000).

14. A-M. Harte, N. A. Fleck, and M. F. Ashby, Acta Mater. 47, 2511 (1999). 